Endocrinol. Japon. 1973, 20 (6), 555 564

\title{
Further Studies on the Localization of Peroxidase in Pig Thyroid Cells
}

\author{
TOICHIRo HOSOYA, Shigeru MATSUKAWA AND Yukifumi NAGAI \\ Department of Physical Biochemistry, Faculty of \\ Pharmaceutical Sciences, Kanazawa University, Kanazawa 920
}

\begin{abstract}
Synopsis
Previously the authors reported that thyroid peroxidase is bound mainly on the membranes of rough-surfaced endoplasmic reticulum. In the present paper, the question whether the enzyme is also contained in other subcellular organelles in the cells or not was investigated. Attempts to isolate plasma membranes and Golgi membranes were made, being monitored by following $\mathrm{Na}^{+}, \mathrm{K}^{+}$-ATPase and galactosyltransferase activities, respectively, through differential centrifugation and twice-repeated sucrose gradient centrifugation. The final preparations showed properties characteristic of these membranes and specific activities comparable to those of reported preparations of liver, but revealed practically no peroxidase activity. The buoyant densities of the $\mathrm{Na}^{+}, \mathrm{K}^{+}$-ATPaseand galactosyltransferase-associated particulates were around 1.136 and 1.154 , respectively, while that of peroxidase-associated particulates (rough-surfaced endoplasmic reticulum) was about 1.192 . Isolated nuclei did not show any peroxidase activity and the behaviour of both mitochondria and lysosomes was different from that of the peroxidaseassociated particulates. Thus, all the results obtained in the present experiments are not favorable to the view that peroxidase is located in nuclei, mitochondria, lysosomes, Golgi apparatus and plasma membranes (microvilli) of thyroid cells.
\end{abstract}

It is well established that the thyroid gland involves a peroxidase (EC 1.11.1.7) which takes a central role in the iodination of thyroglobulin and synthesis of thyroxine. Most biochemical studies indicated that the enzyme is not in a soluble state in the cells but firmly bound to cytoplasmic particulates (Hosoya et al., 1962; Klebanoff et al., 1962; DeGroot and Davis, 1962; Benabdeljlil et al., 1967; Ljunggren and Åkeson, 1968; Nagataki et al., 1973). Attempts to solubilize the enzyme from the particulates and to purify it have been made in several laboratories, agreeing with each other on the point that the enzyme is of a hemoprotein nature (Hosoya and Morrison, 1967a, 1967b; Ljunggren and Åkeson, 1968; Taurog et al., 1970; Nagasaka

\footnotetext{
Received for pubication September 21, 1973.

*This work was supported in pary by a grant from the Ministry of Education of Japan.
}

et al., 1971; Danner and Morrison, 1971; Pommier et al., 1972). However, a concensus has not been attained on the site of the enzyme in the cells. Peroxidase has been reported to be present in Golgi apparatus (Strum and Karnovsky, 1970), mitochondrial fraction (Taurog, 1970), nuclear envelopes (Nakai and Fujita, 1970; Strum and Karnovsky, 1970), colloid lumen (De Robertis and Grasso, 1946; Strum and Karnovsky, 1970) and microvilli (Benabdeljlil et al., 1967; Taurog, 1970; Tice and Wollman, 1972). The location of peroxidase in microvilli was thought by these workers to be relevant to silver grains of radioiodine observed in a number of autoradiographic studies (Nadler and Leblond, 1955; Stein and Gross, 1964; Wollman, 1965; Fujita, 1969; Nadler and Chajut, 1972). On the other hand, the results the present authors obtained in biochemical experiments invari- 
ably indicated that the major site of the enzyme is presumably membranes of $\mathrm{rER}^{* 1}$ ) (Hosoya and Ui, 1961; Hosoya et al., 1963; Hosoya and Morrison, 1967b; Hosoya et al., 1971). These studies, however, did not rule out the possibility that the enzyme may be also present to even a small degree in other organelles in the cells. The present paper describes the results of a further survey for peroxidase activity in thyroid cells. A preliminary account of this work has already been presented (Hosoya et al., 1973).

\section{Materials and Methods}

Porcine thyroid glands were obtained at the local slaughter house and transported on ice to the laboratory. The glands were freed of connective tissue and fat, sliced with a razor blade and washed well with cold saline. All manipulations in the following procedures were conducted at $0 \sim 4^{\circ}$.

For the isolation of $\mathrm{Na}^{+}, \mathrm{K}^{+}$-ATPase-rich plasma membrane fraction, the slices were processed as follows. The slices were homogenized in 3 volumes of medium A with $5 \mathrm{sec}$ burst of Ultra Turrax at 73 volts twice and rehomogenized by one stroke of a glassTeflon homogenizer. The sediments obtained by centrifugation at $50 \times \mathrm{g}^{* 2)}$ for $5 \mathrm{~min}$ were resuspended in medium $\mathrm{A}$, homogenized with the glass-Teflon homogenizer and centrifuged again. The supernatants were combined and spun at $600 \times \mathrm{g}$ for $10 \mathrm{~min}$. The sediments were washed twice with medium $\mathrm{A}$ by repeating homogenization and centrifugation. The supernatants were combined and the volume was adjusted by adding enough medium to give a cytoplasmic extract $(E)$, which was $10 \mathrm{~m} l$ per $\mathrm{g}$ starting slice. The cytoplasmic extract was centrifuged at $25,000 \times \mathrm{g}$ for $10 \mathrm{~min}$ and the sediments obtained

*1) Abbreviations used are: ER, endoplasmic reticulum; rER, rough-surfaced endoplasmic reticulum; sER, smooth-surfaced endoplasmic reticulum; $\mathrm{Na}^{+}, \mathrm{K}^{+}$-ATPase, $\mathrm{Na}^{+}, \mathrm{K}^{+}$-stimulated adenosine triphosphatase (EC 3.6.1.3); medium A, $0.25 \mathrm{M}$ sucrose containing $0.1 \mathrm{mM}$ $\mathrm{MgCl}_{2}$ and $20 \mathrm{mM}$ Tris-HCl buffer, $\mathrm{pH}$ 7.4; medium B, $0.5 \mathrm{M}$ sucrose containing $37.5 \mathrm{mM}$ Tris-maleate buffer, $\mathrm{pH} 6.5$, and $5 \mathrm{mM} \mathrm{MgCl} 2$; medium $\mathrm{C}, 0.25 \mathrm{M}$ sucrosse containing $3 \mathrm{mM}$ $\mathrm{CaCl}_{2}$; medium $\mathrm{D}, 2.2 \mathrm{M}$ sucrose containing $3 \mathrm{mM} \mathrm{CaCl}$.

*2) Indicating always average values for gravity force as used in our previous papers. were suspended in medium $\mathbf{A}$ with one-tenth volume of the cytoplasmic extract used. The suspension was referred to as Fraction M.*3) The suspension was $^{*}$ diluted with $0.25 \mathrm{M}$ sucrose to give a protein concentration of $5 \mathrm{mg} / \mathrm{ml}$ and $20 \mathrm{~m} l$ of the suspension was overlaid on $20 \mathrm{ml}$ of $0.32 \mathrm{M}(10.6 \%)^{* 4)}$ sucrose placed on $50 \mathrm{~m} l$ of $1.2 \mathrm{M}(35.6 \%)$ sucrose in a $94 \mathrm{~m} l$ centrifuge tube. After centrifugation at $95,000 \times \mathrm{g}$ for $50 \mathrm{~min}$ in a Type 42 rotor, a milky band at the interface was collected and diluted with 2 volumes of cold distilled water. The suspension was spun at $75,000 \times \mathrm{g}$ for $30 \mathrm{~min}$ and the pellets obtained was resuspended in a small volume of $0.25 \mathrm{M}$ sucrose and designated as M 3-1. Three $\mathrm{m} l$ of $\mathrm{M}$ 3-1 suspension was mixed with $2 \mathrm{ml}$ of $0.1 \mathrm{M}$ Tris- $\mathrm{HCl}$ buffer, $\mathrm{pH}$ 8.5 , and then $50.0 \%$ sucrose was added to give a $35.0 \%$ sucrose suspension. Thirteen $\mathrm{m} l$ of the suspension was placed in the bottom of $38.5 \mathrm{ml}$-centrifuge tube and overlaid with the following step-gradient: $15 \mathrm{~m} l$ of $32.0 \%$ sucrose and $8 \mathrm{~m} l$ of $8.4 \%$. After centrifugation at $81,500 \times \mathrm{g}$ for $150 \mathrm{~min}$, the interface layer between $8.4 \%$ and $32.0 \%$ was collected, diluted with 3 volumes of distilled water and centrifuged at $75,000 \times \mathrm{g}$ for $30 \mathrm{~min}$. The pellets obtained were suspended in a small volume of $0.25 \mathrm{M}$ sucrose and designated as $\mathrm{M}$ 3-1-1.

For the isolation of Golgi membrane-rich fraction, the thyroid slices (usually 30 40 g) were homogenized in one volume of medium B with a $5 \mathrm{sec}$ burst of Ultra Turrax at 73 volts and rehomogenized by one stroke of a loosely-fitted glass-Teflon homogenizer. The homogenates were passed through four layers of nylon cloth and the volume adjusted to become $4 \mathrm{~m} l$ per $\mathrm{g}$ of wet tissue by the addition of medium $\mathrm{B}$, and the suspension was centrifuged at $600 \times \mathrm{g}$ for $10 \mathrm{~min}$. The supernatant (cytoplasmic extract) was separated into three particulates fractions ( F 1, F 2 and F 3) and a soluble fraction by successive centrifugation at $2,000 \times \mathrm{g}$ for $10 \mathrm{~min}, 10,000 \times \mathrm{g}$ for $10 \mathrm{~min}$ and $105,000 \times \mathrm{g}$ for $60 \mathrm{~min}$, respectively. The second fraction, F 2, was richest in galactosyltransferase activity and subjected to discontinuous sucrose gradient centrifugation. Fifty $\mathrm{m} l$ of $\mathrm{F} 2$ suspension in $16.0 \%$ sucrose $(5 \mathrm{mg}$ protein per $\mathrm{m} l)$ was layered on $40 \mathrm{~m} l$ of $37.0 \%$ sucrose in a $90 \mathrm{~m} l$-centrifuge tube. After centrifugation at $95,500 \times \mathrm{g}$ for 90 min, a milky band at the interface of the discontinuous sucrose gradient, F 2-1, and pellets at the bottom, F 2-2, were recovered. The former was

*3) Previously, the corresponding fraction was referred to as Fraction M $+\mathrm{L}$ (Hosoya et al., 1971), but here this fraction is referred to as Fraction $\mathrm{M}$ for the sake of convenience.

*4) Percentage of sucrose solution is always expressed by weight/weight. 
diluted with 3 volumes of cold distilled water and the suspension was centrifuged at $105,000 \times \mathrm{g}$ for $60 \mathrm{~min}$ to obtain precipitates, which was then suspended in a small volume of $37.0 \%$ sucrose. Fifteen $\mathrm{ml}$ of the suspension $(1.4 \mathrm{mg}$ protein per $\mathrm{ml}), 14 \mathrm{ml}$ of $33 \%$ sucrose and $5.5 \mathrm{~m} l$ of $27.0 \%$ sucrose were successively placed in a $38.5 \mathrm{~m} /$-centrifuge tube and centrifuged at $81,500 \times \mathrm{g}$ for $120 \mathrm{~min}$ in a SW 27 rotor. Milky bands at each interface layer were withdrawn and diluted separately 3 volumes of distilled water, centrifuged at $105,000 \times \mathrm{g}$ for $60 \mathrm{~min}$ and the pellets were suspended in $1.6 \mathrm{~m} l$ of medium $B$ and designated as F 2-1-1 (from the upper layer) and F 2-1-2 (from the lower layer), respectively. Occasionally, F 2-2 was also separated into two subfractions, F 2-2-1 and F 2-2-2, as follows. The pellets, F 2-2, were suspended in medium $\mathrm{B}$ to become $2.5 \mathrm{mg}$ protein per $\mathrm{m} l$ and $50 \mathrm{ml}$ of the suspension was layered over $20 \mathrm{ml}$ of $37.0 \%$ sucrose which was placed on $20 \mathrm{ml}$ of $42.0 \%$ sucrose at the bottom of a $90 \mathrm{ml}$-centrifuge tube. After centrifugation at $95,500 \times \mathrm{g}$ for $90 \mathrm{~min}$, two layers at the interfaces of discontinuous sucrose were recovered and treated as described in the case of F 2-1.

The isolation of thyroid nuclei was performed as follows. Thyroid glands were well perfused with cold $0.9 \% \mathrm{NaCl}$ solution, sliced and washed in the $\mathrm{NaCl}$ solution. About $10 \mathrm{~g}$ of the slices were homogenized in 10 volumes of medium $C$ with two $10 \mathrm{sec}$ burst of a Waring blendor, rehomogenized by 2 strokes of a glass-Teflon homogenizer and the homogenate was passed through two layers of gauze and centrifuged at $600 \times \mathrm{g}$ for $10 \mathrm{~min}$. The pellets obtained were suspended in $20 \mathrm{ml}$ of the same medium and spun at $600 \times \mathrm{g}$ for $10 \mathrm{~min}$. This washing was repeated twice. An aliquot of the pellets (crude nuclei) was suspended in $0.25 \mathrm{M}$ sucrose and used for the assay of peroxidase. Most of the pellets remaining were suspended in $12 \mathrm{ml}$ of medium D. Each $4 \mathrm{~m} /$ of the suspension was layered over $1 \mathrm{~m} l$ of the same medium in a $5 \mathrm{~m} l$-centrifuge tube to obtain pellets (purified nuclei) by centrifugation at 73,500 $\times \mathrm{g}$ for $30 \mathrm{~min}$ in a Hitachi swinging rotor (RPS 40A). In a few cases, the pellets were suspended in the medium $\mathrm{D}$ to repeat the same process for obtaining further purified nuclei.

The activities of peroxidase, cytochrome oxidase (EC 1.9.3.1) and $\mathrm{Na}^{+}, \mathrm{K}^{+}$-ATPase were measured and expressed as described previously (Hosoya et al., 1971). The assay procedure and expression of enzyme unit of acid phosphatase (EC 3.1.3.2) was the same as De Duve et al. (1955) employing $\beta$-glycerophosphate (British House Ltd) as the substrate. Galactosyltransferase was assayed by the method of Morré et al. (1970) and the enzyme amount which catalysed the transfer of one nmole of galactose per $\mathrm{hr}$ under the conditions was defined as one unit. In this reaction, the formation of $\mathrm{N}$-acetyllactosamine was checked using an authentic compound (a gift from Prof. Yoshizawa) by paper chromatography (Solvent system, $n$-propanol: ethylacetate: water $=7: 1: 2 \mathrm{v} / \mathrm{v} ; \quad \mathrm{R}_{f}=$ $0.313,0.388$ and 0.524 for $\mathrm{N}$-acetyllactosamine, galactose and $\mathrm{N}$-acetyl-D-glucosamine, respectively). UDP $\left[{ }^{14} \mathrm{C}\right]$ galactose, uniformly labeled $\left(234 \mathrm{mC}_{i} /\right.$ mmole), was obtained from the Radiochemical Center, Amsterdam, UDP-galactose from Sigma Chemical Corp. and N-acetyl-D-glucosamine from Nakarai Chemical Ltd. Protein and RNA were determined as described previously (Hosoya et al., 1971). DNA was determined by Burton's method (1956) using calf thymus DNA (Sigma Chemical Corp.) as standard.

\section{Results}

$\mathrm{Na}^{+}, \mathrm{K}^{+}-\mathrm{ATPase}$-associated plasma mem-
branes

The isolation of plasma membranes is usually conducted by assaying $5^{\prime}$-nucleotidase, $\mathrm{Na}^{+}$, $\mathrm{K}^{+}$-ATPase, alkaline phosphatase, leucine aminopeptidase or adenyl cyclase (Depierre and Karnovsky, 1973). Among these enzymes, we employed $\mathrm{Na}^{+}, \mathrm{K}^{+}$-ATPase because the enzyme was biochemically confirmed to be located in the plasma membrane fraction of thyroid (Wolff and Jones, 1971) and stained histochemically in microvillous cell border of apical plasma membranes (Shimazaki et al., 1967). The chemical and enzymatic composition, together with the electron microscopic observation, indicated that our preparation consists mainly of plasma membranes, as described elsewhere (Nagai and Hosoya, 1974). The data shown in Table 1 indicate that proxidase was excluded by the second sucrose gradient centrifugation and not present in the final preparation, M 3-1-1.

\section{Golgi membranes}

For the isolation of Golgi membranes, galactosyltransferase was employed as a marker enzyme because this enzyme was found to be involved in the thyroidal Golgi apparatus (Herscovics, 1969; Bouchilloux et al., 1970). The cytoplasmic extract in $0.5 \mathrm{M}$ sucrose was 
Table 1. Activities of $\mathrm{Na}^{+}, \mathrm{K}^{+}$-ATPase and peroxidase, and amount of protein in each step for isolation of $\mathrm{Na}^{+}, \mathrm{K}^{+}$-ATPase-rich particulates. The isolation procedure is described in the text.

\begin{tabular}{lccc}
\hline \multirow{2}{*}{ Fraction } & \multicolumn{3}{c}{ Relative values of } \\
\cline { 2 - 4 } & Protein & $\mathrm{Na}^{+}, \mathrm{K}^{+}$-ATPase & Peroxidase \\
\hline Cytoplasmic extract $(\mathrm{E})^{*}$ & $(100)$ & $(100)$ & $(100)$ \\
M & 12.4 & 110.2 & 38.2 \\
M 3-1 & 0.93 & 55.9 & 8.8 \\
M 3-1-1 & 0.19 & 15.0 & $\sim 0$ \\
\hline
\end{tabular}

* Absolute values were $108 \mathrm{mg}, 0.65$ units and $0.075 \mathrm{GU}$ per $\mathrm{g}$ tissue for protein, $\mathrm{Na}^{+}, \mathrm{K}^{+}$-ATPase and peroxidase, respectively.

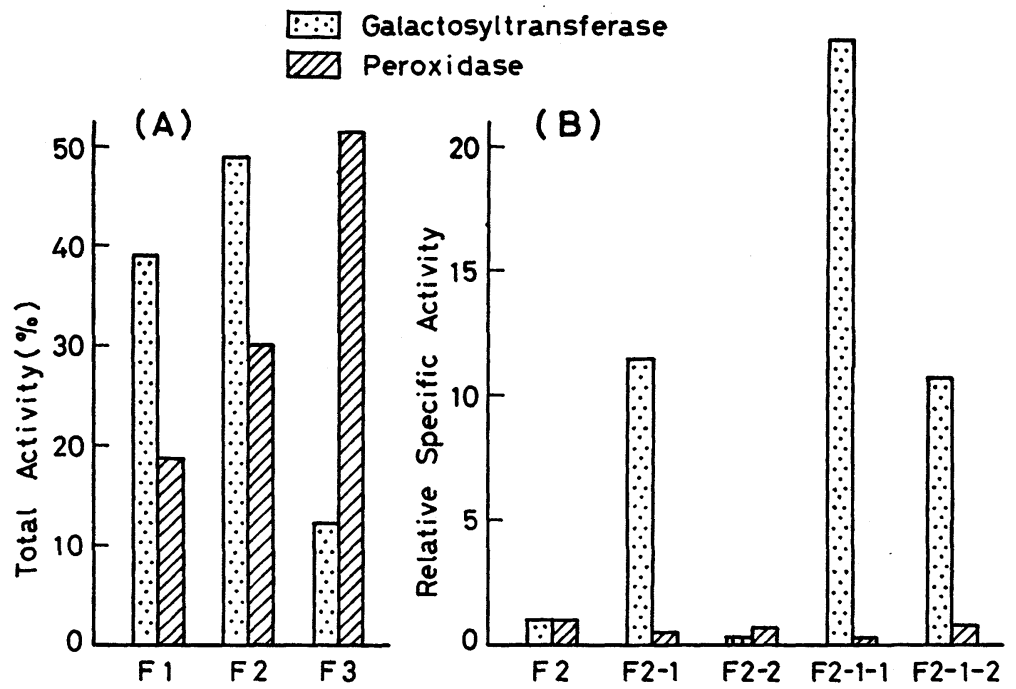

Fig. 1. Distribution of galactosyltransferase and peroxidase in subcellular fractions obtained by differential centrifugation, (A), and by sucrose gradient centrifugation, (B). The isolation procedure of these fractions is described in Materials and Methods. In the left hand figure, (A), the sum of F 1, F 2 and F 3 was taken as 100 (absolute values of galactosyltransferase and peroxidase being $107 \mathrm{units} / \mathrm{g}$ tissue and $0.100 \mathrm{GU} / \mathrm{g}$ tissue, respectively). In the right hand figure, $(B)$, the specific activity of $F 2$ was taken as 1.0 (absolute values of galactosyltransferase and peroxidase being 7.82 units/mg protein and $0.0056 \mathrm{GU} / \mathrm{mg}$ protein, respectively). Mean values for the two experiments were presented.

separated by the successive centrifugation into three particulate fractions (F 1, F 2 and F 3), and then the second fraction; F 2, was further subjected twice to discontinuous sucrose gradient centrifugation. The result depicted in Figure 1 indicates that galactosyltransferaseassociated particulates showed a tendency to sediment at a lower centrifugal force and to be of lower density than peroxidase-associated particulates. Thirteen per cent of the total activity of galactosyltransferase in the original particulates fraction was recovered in the final fraction, F 2-1-1, and its specific activity was comparable to that of the preparations derived from the liver tissue, $230 \sim 350$ nmoles per $\mathrm{mg}$ protein, (Fleischer and Fleischer, 1970; Kato 


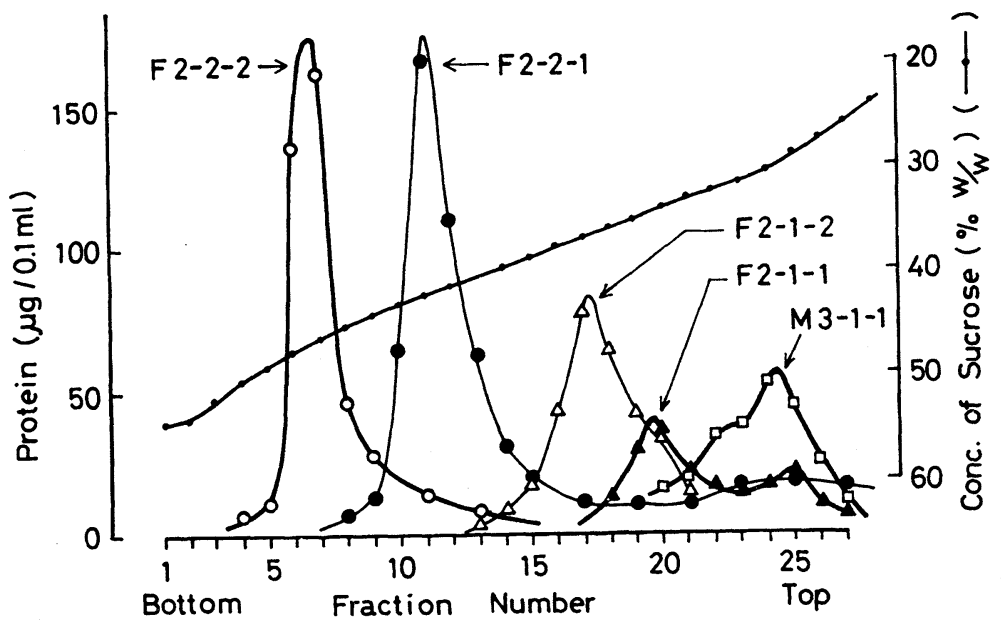

Fig. 2. Isopycnic centrifugation of five subcellular fractions.

Each $2 \mathrm{~m} l$ of $0.5 \mathrm{M}$ sucrose suspension of four fractions derived from $\mathrm{F} 2$ (F 2-1-1, F 2-1-2, F 2-2-1 and F 2-2-2) and of M 3-1-1 (0.72, 3.0, 6.0, 6.0 and $1.16 \mathrm{mg}$ protein $/ \mathrm{ml}$, respectively) was separately layered on the top of $30 \mathrm{ml}$ of 25.0 to $45.0 \%$ linear sucrose gradient which was placed on $5 \mathrm{ml}$ of $55.0 \%$ sucrose in the $38.5 \mathrm{ml}$ centrifuge tubes. After centrifugation at $81,500 \times \mathrm{g}$ for $15 \mathrm{hr}$ in a Beckman SW 27 rotor, fourteen drop fractions were collected from the bottom and an aliquot was used for the determination of protein and of sucrose density by a refractometer. The data for the five centrifuge tubes are superposed in this figure.

et al., 1971), while peroxidase activity in F 2-1-1 was extremely small. Confirming these results, it was found by electron microscopy that the fraction scarcely contains any rER but contains sac- and tubular-like vesicles and small fragments similar to those found in the case of liver by Fleischer and Fleischer (1970).

In order to compare the buoyant density of galactosyltransferase-associated particulates with that of peroxidase-bound ones, F 2-1-1 and F 2-1-2 were subjected to isopycnic centrifugation, together with $\mathrm{F} 2-2-1$ and F 2-2-2 which were derived from the peroxidase-rich fraction, F 2-2. For comparison, a $\mathrm{Na}^{+}, \mathrm{K}^{+}$-ATPase-rich fraction, M3-1-1, prepared as described above, was also run parallel with them. After 15-hr centrifugation, protein in each fraction was distributed as depicted in Figure 2, showing each of the main bands located at different levels. The peaks of the protein concentration in these fractions were at densities of $1.136,1.154$, $1.163,1.192$ and $1.218 \mathrm{~g} / \mathrm{cm}^{3}$ for $\mathrm{M} \mathrm{3}-1-1$,
F 2-1-1, F 2-1-2, F 2-2-1 and F 2-2-2, respectively. Specific activities of four enzymes at the peak are shown in Figure 3. This figure indicates that peroxidase was not encounted in galactosyltransferase-rich fraction while the latter enzyme was somewhat distributed in F 2-1-2 (presumably sER) and F 2-2-1 (rER). No peroxidase was found in the peak fraction of M 3-1-1 (plasma membranes) or of F 2-2-2 (mitochondria).

\section{Lysosomes}

Our previous results suggested that, although the distribution of acid phosphatase activity considerably overlapped with that of peroxidase activity, peroxidase may not be related to lysosomes in view of a difference in the pattern of specific activity of the two enzymes in subcellular fractions (Hosoya, 1963; Hosoya et al., 1971). This has been further confirmed from the results depicted in Figure 4. In this experiment, an acid phosphataserich fraction, Fraction $L_{a}$, (see Hosoya, 


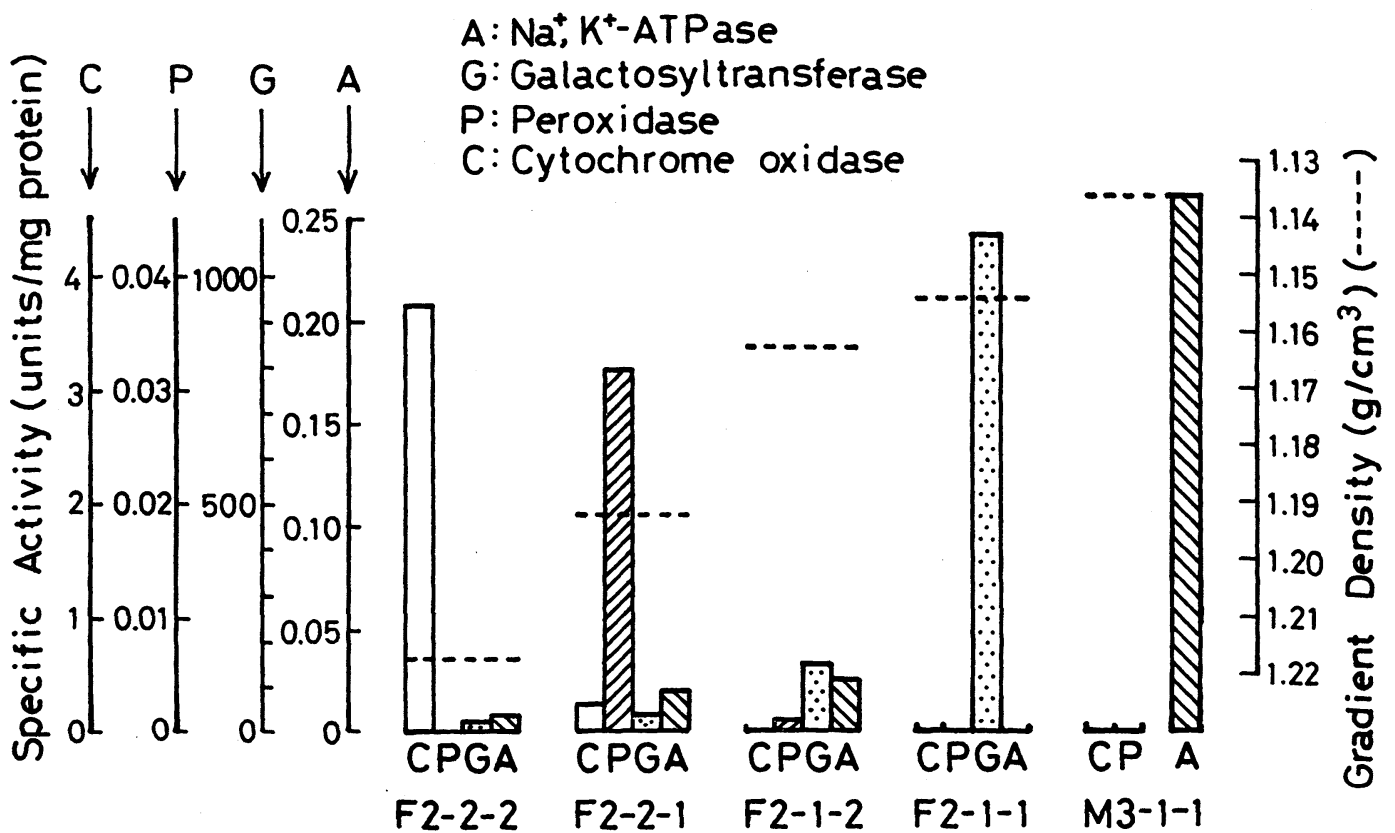

Fig. 3. Specific activities of four enzymes and densities at the position of the protein peak shown in Figure 2.

Fractions assayed were No. 7 of F 2-2-2, No. 11 of F-2-2-1, No. 18 of F 2-1-2, No. 20 of F 2-1-1 and No. 24 of M 3-1-1. Densities were calculated from the values for sucrose concentration of these fractions as shown in Figure 2.

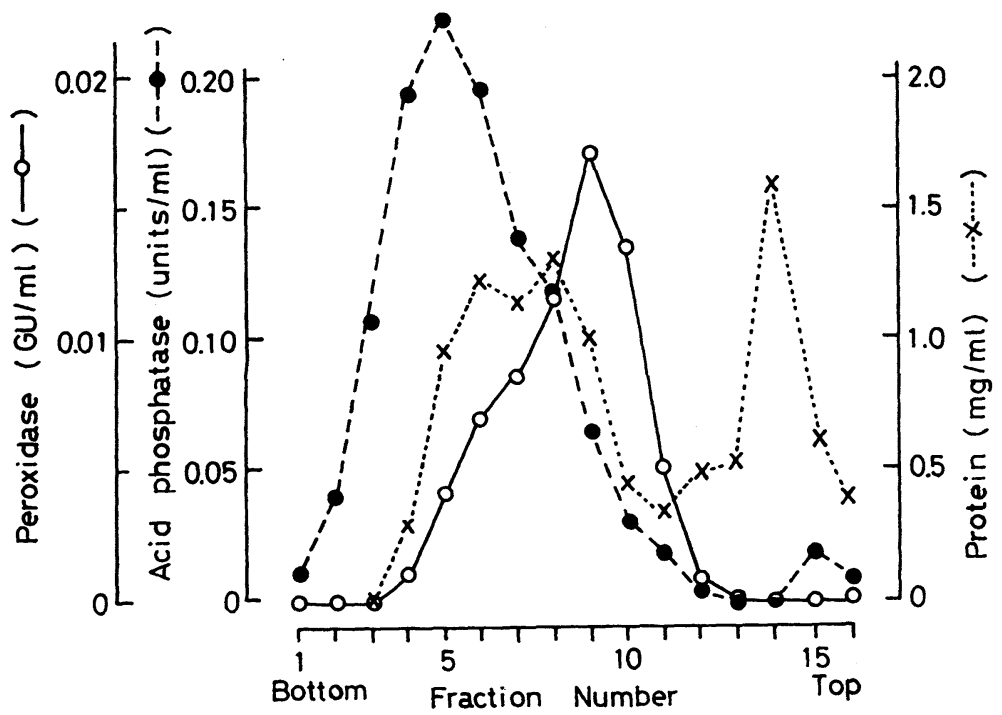

Fig. 4. Sucrose gradient centrifugation of a acid phosphatase-rich particulate fraction. The particulate fraction used was sediments between $100,000 \mathrm{~g} \cdot \mathrm{min}$ and $250,000 \mathrm{~g} \cdot \mathrm{min}$ from cytoplasmic extract, corressponding to Fraction $\mathrm{L}_{a}$ of the previous paper(Hosoya et al., 1963). $0.5 \mathrm{ml}$ of the suspension $(10 \mathrm{mg}$ protein $/ \mathrm{ml}$ ) was layered on the top of multi-layer sucrose gradient $(0.5 \mathrm{~m} l$ each of $1.8,1.6,1.4,1.3,1.2,1.0,0.8$ and $0.6 \mathrm{M}$ from bottom to top) in a $5 \mathrm{ml}$-centrifuge tube. After centrifugation at $101,000 \times \mathrm{g}$ for $2 \mathrm{hr}$ in a SW 39 rotor, five drop fractions were collected from the bottom and used for the assay of peroxidase and acid phosphatase and for the determination of protein. 
Table 2. Contents of protein and nucleic acids, and activity of peroxidase in nuclear preparations. The procedure for the preparation is described in the text.

\begin{tabular}{|c|c|c|c|c|}
\hline & Fraction & $\begin{array}{l}\text { Peroxid } \\
\text { Total } \\
\left(\frac{\mathrm{GU} \times 10^{3}}{\mathrm{~g} \text { thyroid }}\right)\end{array}$ & $\begin{array}{l}\text { se activity } \\
\text { Specific } \\
\left(\frac{\mathrm{GU} \times 10^{3}}{\mathrm{mg} \text { protein }}\right)\end{array}$ & Protein: DNA: RNA \\
\hline \multirow{4}{*}{ Exp. 1} & Cytoplasmic extract (E) & 422.0 & 6.76 & \\
\hline & Crude nuclear fraction & 2.2 & 0.77 & $5.7: 1: 0.091$ \\
\hline & Purified nuclear fraction & & 0.037 & $4.7: 1: 0.091$ \\
\hline & Further purified nuclear fraction & & $\sim 0$ & $4.9: 1: 0.071$ \\
\hline \multirow{2}{*}{ Exp. 2} & Cytoplasmic extract (E) & & 5.49 & \\
\hline & Purified nuclear fraction & & $\sim 0$ & $2.9: 1: 0.077$ \\
\hline
\end{tabular}

1963), was centrifuged at $101,000 \times \mathrm{g}$ for $2 \mathrm{hr}$ in a sucrose gradient. The centrifugation was not enough to attain a state of equilibration and to estimate the buoyant density of acid phosphatase-associated particulates, but sufficient to indicate that those were heavier than peroxidase-bound particulates. That the former contains so-called lysosomes of thyroid (Wollman et al., 1964; Seljelid, 1965; Ekholm et al., 1966) was confirmed from the following observations: (1) Electron microscopic examination showed that No. 5 fraction, which was highest in acid phosphatase activity, consisted mainly of spherial or ovoid dense bodies similar to those found in liver tissue. (2) When Gomori's histochemical method (Gomori, 1952) was applied to the No. 5 fraction, black reaction products of acid phosphatase was deposited within the dense bodies. The reaction product was entirely eliminated by heat treatment or in the presence of KF. (3) Treatment with pH 5 medium at $37^{\circ}$ before incubation caused leakage of the dark reaction product outside of the dense bodies. On the other hand, the main components in the No. 9 fraction of Figure 4 were rough microsomes as found in Fraction IV of the previous paper (Hosoya et al., 1971).

\section{Nuclei}

The nuclei of thyroid cells were isolated and purified essentially by the method of Amano (1967). When examined with both light and electron microscopes, the crude preparation was still seen to be contaminated with cytoplasmic elements, while the purified preparation contained practically no contaminants. In agreements with these observations, peroxidase activity was not found in the purified nuclei, as shown in Table 2.

\section{Discussion}

Although the presence of thyroid peroxidase on nuclear envelopes was reported in some histochemical studies at the electron microscopic level (Strum and Karnovsky, 1970; Nakai and Fujita, 1970; Tice and Wollman, 1972), the results of most biochemical studies were not favorable to the view (Hosoya et al., 1962; DeGroot and Davis, 1962; Hosoya et al., 1971; Nagataki et al., 1973). The present experiments on purified nuclei also failed to demonstrate the enzyme in the nuclear preparation (Table 2) and caused us to focus our attention on cytoplasm and plasma membranes. Since the major site of the enzyme has been found in ER (Hosoya et al., 1971, 1972), the present study has been devoted to examining whether the enzyme is located in other organelles like mitochondria, lysosomes, Golgi apparatus or plasma membranes.

The present experimental results obtained by sucrose gradient centrifugation (Fig. 2 and Fig. 3) have almost eliminated the possibility that mitochondria and lysosomes carry peroxidase. The peroxidase activity often found in 
the mitochondrial fraction obtained by differential centrifugation may be well explained by contaminating microsomes (Hosoya et al., 1971) or fragments of rER which were imcompletely detached from surrounding mitochondria (Hosoya et al., 1972). The absence of peroxidase in lysosomes seems to diminish the possibility that thyroglobulin incorporated into colloid droplets may be iodinated when they fuse with lysosomes (Wetzel et al., 1965; Seljelid, 1965).

It is well known that the cytoplasms of liver, kidney and other tissues contain a kind of subcellular vesicles called peroxisomes (morphologically microbodies), which posses catalase, L- $x$-hydroxy acid oxidase and uricase and can produce hydrogen peroxide (De Duve and Baudhuin, 1966). However, to our knowledge, the presence of such particles in thyroid cells has not been reported and we ourselves have been able to detect neither catalse nor $\mathrm{L}-\alpha$ hydroxy acid oxidase activity in cytoplasmic particulates, as mentioned previously (Hosoya et al., 1971).

It is reported that the ends of Golgi apparatus and tubular sER are connected to each other and share some kinds of enzymes (Fleischer and Fleischer, 1970). This wakened an expectation that thyroidal Golgi apparatus may involve peroxidase, but the results presented in Figure 2 and Figure 3 tend to deny this possibility. Nevertheless, galactosyltransferase may be distributed to some degree in sER since its specific activity in F 2-1-2 attained to about one-sixth of that of $F$ 2-1-1.

In connection with the distribution of these enzymes, it is interesting to note the densities of subcellular particulates in thyroid cells and to compare them with those of liver. The density of Golgi membranes of pig thyroid seems to correspond to that of liver, 1.12 1.14, (Fleischer and Fleischer, 1970; Morré et al., 1970), because the galactosyltransferase activity had a peak in a fraction with density of 1.154 (Fig. 3). The densities of rough and smooth microsomes of rat liver were reported to be around 1.206 and 1.167 , respectively,
(Lee et al., 1969; Breillat, 1973), and these coincide with densities at a peak peroxidase activity of F 2-2-1, 1.192, and of F 2-1-2, 1.163. The density of mitochondria of pig thyroid, 1.218, also agrees with the reported values for rat liver, 1.217 (Beaufay et al., 1959).

Whether peroxidase exists on microvillous cell border is an important problem, in view of its relationship to the iodination of thyroglobulin. Although some workers reported the presence of the enzyme on microvilli by histochemical studies (Strum and Karnovsky, 1970; Tice and Wollman, 1972) and by biochemical studies (Benabdeljlil et al., 1967; Taurog, 1970), the present experimental results on isolated plasma membranes did not offer evidence favorable to the idea. In the manipulation for isolation, we employed, as a marker enzyme, $\mathrm{Na}^{+}, \mathrm{K}^{+}$-ATPase which was reported to be located on apical membranes as well as basal membranes (Shimazaki et al., 1967) and took advantage of the difference in density for its separation from other organelles. Therefore, it is expected that the fragments of microvilli, as a portion of apical membranes, should come into the preparation. It seems to be quite improbable that the density of microvilli is as great as that of rough microsomes.

In conclusion, the reasonable deduction from this study is that it is unlikely that peroxidase is contained in nuclei, mitochondria, lysosomes and plasma membranes, although it is usually difficult to draw conclusion about the complete absence of anything. Thus, the site of peroxidase must be almost confined to rER and sER as mentioned previously (Hosoya et al., 1971, 1972). It remains to explain the relationship of the site of peroxidase to the iodination of thyroglobulin. We wish to deal with this problem in the next paper which is to describe the experimental results concerning the site of iodination of thyroglobulin. 


\section{Acknowledgements}

The authors wish to thank Prof. Yoriaki Kurata (Cancer Institute, Kanazawa University) and Dr. Masukichi Okada (Tokyo Education University) for their help in the electron microsccpic observation. Thanks are also due to Prof. Zensaku Yoshizawa (Tohoku University) for the gift of $\mathrm{N}$-acetyllactosamine and Prof. Keitaro Kato (Kyushu University)for their valuable suggestion on the isolation procedure of Golgi membranes.

\section{References}

Amano, M. (1967). Exp. Cell Res, 46, 169.

Beaufay, H., D. S. Bendall, P. Baudhuin, R. Wattiaux and C. De Duve (1959). Biochem. $J .73,628$.

Benabdeljlil, C. M., M. Michel-Béchet and S. Lissitzky (1967). Biochem. Biophys. Res. Commun. 27, 74.

Bouchilloux, S., O. Chabaud, M. MichelBéchet, M. Ferrand and A. M. AthouëlHaon (1970). Biochem. Biophys. Res. Commun. 40, 314.

Breillatt, J. P. (1973). Biochem. Biophys. Acta 291, 83.

Burton, K. (1956). Biochem. J. 62, 315.

Danner, D. J. and M. Morrison (1971). Biochem. Biophys. Acta 235, 44.

De Duve, C. and P. Baudhuin (1966). Physiol. Rev. 46, 323.

De Duve, C., B. C. Pressman, R. Gianetto, R. Wattiaux and F. Appelman (1955). Biochem. J. 60, 604.

DeGroot, L. J. and A. M. Davis (1962). Endocrinology 70, 492.

DePierre, J. W. and M. L. Karnovsky (1973). J. Cell Biol. 56, 275.

De Robertis, E. and R. Grasso (1946). Endocrinology 38, 137.

Ekholm, R., S. Smeds and U. Strandberg (1966). Exp. Cell Res. 43, 506.

Fleischer, B. and S. Fleischer (1970). Biochim. Biophys. Acta 219, 301.

Fujita, H. (1969). Virchows Arch. A. B. Z. 2, 265.
Gomori, G. Microscopic Histochemistry: Principles and Practice, University of Chicago Press, Chicago, p. 273 (1952).

Chicago Press, p. 273 (1952).

Herscovics, A. (1969). Biochem. J. 112, 709.

Hosoya, T. (1963). J. Biochem. 53, 86.

Hosoya, T., and N. Ui (1961). Nature, 192, 659.

Hosoya, T., Y. Kondo and N. Ui (1962). J. Biochem. 52, 180.

Hosoya, T., S. Matsukawa and Y. Kurata (1972). Endocrinol. Japon. 19, 359.

Hosoya, T., S. Matsukawa and Y. Nagai (1971). Biochemistry 10, 3086.

Hosoya, T., S. Matsukawa and Y. Nagai. In: Progress in Endocrinology, Proceedings IV International Congress of Endocrinology, Washington 1972, Excerpta Medica, Amsterdam, p. 1009 (1973).

Hosoya, T. and M. Morrison (1967a). J. Biol. Chem. 242, 2828.

Hosoya, T. and M. Morrison (1967b). Biochemistry 6, 1021.

Kato, K., S. Kawamoto, H. Tsuji and H. Tsukamoto (1971). J. Japan. Biochem. Soc. 43, 657. (In Japanese).

Klebanoff, S. J., C. Yip and D. Kessler (1962). Biochim. Biophys. Acta. 58, 563.

Lee, T-C., D. C. Schwartzendruber and F. Synder (1969). Biochem. Biophys. Res. Commun. 36, 748.

Ljunggren, J-G. and $\AA$, Åkeson (1968). Arch. Biochem. Biophys. 127, 346.

Morré, D. J., R. L. Hamilton, H. H. Mollenhauer, R. W. Mahley, W. P. Cunningham, R. D. Cheetham and V. S. Lequire (1970). J. Cell. Biol. 44, 484.

Nadler, N. J. and N. R. Chajut. In: Abstracts of IV International Congress of Endocrinology Washington 1972, p. 59 (1972).

Nadler, N. T. and C. P. Leblond (1955). Brookhaven Symp. Biol. 7, 40.

Nagai, Y. and T. Hosoya (1974). J. Biochem. (in press)

Nagasaka, A., L. J. DeGroot, R. Hati and C. Liu (1971). Endocrinology 88, 486.

Nagataki, S., H. Uchiyama, Y. Masuyama and K. Nakao (1973). Endocrinology 92, 
363.

Nakai, Y. and H. Fujita (1970). Z. Zellforsch. $107,104$.

Pommier, J., S. de Prailauné and J. Nunez (1972). Biochimie 54, 483.

Seljelid, R. (1965). J. Histochem. Cytochem. 13, 687.

Shimazaki, M., A. Shiozaki, C. Hiramine, T. Mori, N. Katsu and A. Otsui (1967). Wakayama Medical Reports 11, 143.

Stein, O. and J. Gross (1964). Endocrinology 75, 787.

Strum, J. M. and M. J. Karnovsky (1970). J. Cell Biol. 44, 655.

Taurog, A. (1970). Recent Progr. Hormone
Res. 26, 189.

Taurog., A., M. L. Lothrop, R.W. Estabrook (1970). Arch. Biochem. Biophys. 139, 221.

Tice, L. W. and S. H. Wollman (1972). Laboratory Investigation 26, 63.

Wetzel, R. K., S. S. Spicer and S. H. Wollman (1965). J. Cell. Biol. 25, 593.

Wolff, J. and A. B. Jones (1971). J. Biol. Chem. 246, 3939.

Wollman, S. H. Curr. Top. Thyroid Res., Proc. 5th Int. Thyroid Conf. ed. by C. Cassano and M. Andreoli, Academic Press, p. 1 (1965).

Wollman, S. H., S. S. Spicer and M. S. Burstone (1964). J. Cell Biol. 21, 191. 